\title{
Approach of a Decision Support Matrix for the Implementation of Exoskeletons in Industrial Workplaces
}

\author{
Lennart Ralfs, Niclas Hoffmann and Robert Weidner
}

\begin{abstract}
Despite the advancing trends in automation, workers in industrial workplaces often face repetitive tasks with heavy workloads. Whenever methods or adaptions in both technology and organization are insufficient to improve working conditions, personal-related interventions as exoskeletons come into question. They may prove successful in alleviating musculoskeletal disorders and relieving physical strain. The rising number of market-ready exoskeletons often challenges users or companies to select an appropriate system for their applications. In order to address this issue, this paper presents a generic approach for supporting both the selection and evaluation of exoskeletons. With respect to the task, user, and technical system, the decision support matrix (DSM) merges work profiles, motion patterns, and postures into one schematic representation. It aims to suggest exoskeletons with inherent properties matching these external requirements. In summary, the DSM may help users and companies to assess the fundamental suitability and select appropriate support devices for specific applications.
\end{abstract}

L. Ralfs $(\square) \cdot$ N. Hoffmann $\cdot$ R. Weidner

Chair of Production Technology, Institute of Mechatronic, University of Innsbruck, Innsbruck, Austria

e-mail: Lennart.Ralfs@uibk.ac.at

N. Hoffmann

e-mail: Niclas.Hoffmann@uibk.ac.at; Niclas.Hoffmann@hsu-hh.de

R. Weidner

e-mail: Robert.Weidner@uibk.ac.at; Robert.Weidner@hsu-hh.de

N. Hoffmann $\cdot$ R. Weidner

Laboratory of Manufacturing Technology, University of the Federal Armed Forces Hamburg, Helmut-Schmidt-University, Hamburg, Germany

T. Schüppstuhl et al. (eds.), Annals of Scientific Society for Assembly,

Handling and Industrial Robotics 2021,

https://doi.org/10.1007/978-3-030-74032-0_14 


\section{Keywords}

Exoskeleton $\cdot$ Industrial workplace $\cdot$ Decision Support $\cdot$ Human-machine interaction • Expert system

\section{Introduction}

In recent times, advancing trends in automation and mechanization afford and affect the restructuring of workplaces, as well as the implementation of new technologies in industrial applications (e.g., systems for human-machine cooperation [1], exoskeletons [2], or augmented reality systems [3]). Nevertheless, workers often face heavy workloads, repetitive tasks, or need to perform in ergonomically improvable positions. Almost one in three people manipulates heavyweight goods, 43 percent daily work in either tiring, exhausting, or painful postures [4]. As a result, workers are physically and psychologically stressed and exposed to a risk of developing musculoskeletal disorders (MSD) [4, 5]. One viable option to prevent future and reduce existing effects is the use of exoskeletons [6]. They have shown to support workers at industrial workplaces in repetitive tasks that cannot be fully automated or are physically demanding [7].

Regarding industrial applications, exoskeletons are externally wearable mechanical devices [8] that either empower, facilitate, stabilize, or add movements [9]. Depending on their respective functional and morphological configuration, exoskeletons do not only potentially relieve physical stress on users, but also enhance their performance, strength, and endurance $[10,11]$. Frequent capabilities and purposes of exoskeletons are lifting and manipulation assistance, body stabilization during the execution of manual tasks, and positioning correction [7, 10]. In this sense, exoskeletons amplify users' capabilities and build a bridge between fully manual work and tasks demanding the implementation of industrial robots [7].

\section{Approaches for Classification of Support Situations}

As a wide range of requirements and market-ready exoskeletons exist, selecting the most suitable system for the respective application is complex and challenging. In current science and practice, different approaches exist to characterize support situations for exoskeletons. According to crucial criteria (e.g., power supply mechanism, supported part of body, purpose of use), exoskeletons can be classified into different types or groups, respectively $[8,11]$. In this respect, distinctive features such as affordable dynamics, motion ranges, or postures are of varying importance [12]. Hitting the same notch, checklists from, e.g., assurance associations [13] and calculation tools from manufacturers [14], indicate relevant factors to characterize the support situation. A similar but more illustrative approach is a periodic classification table for technical support systems. It puts 


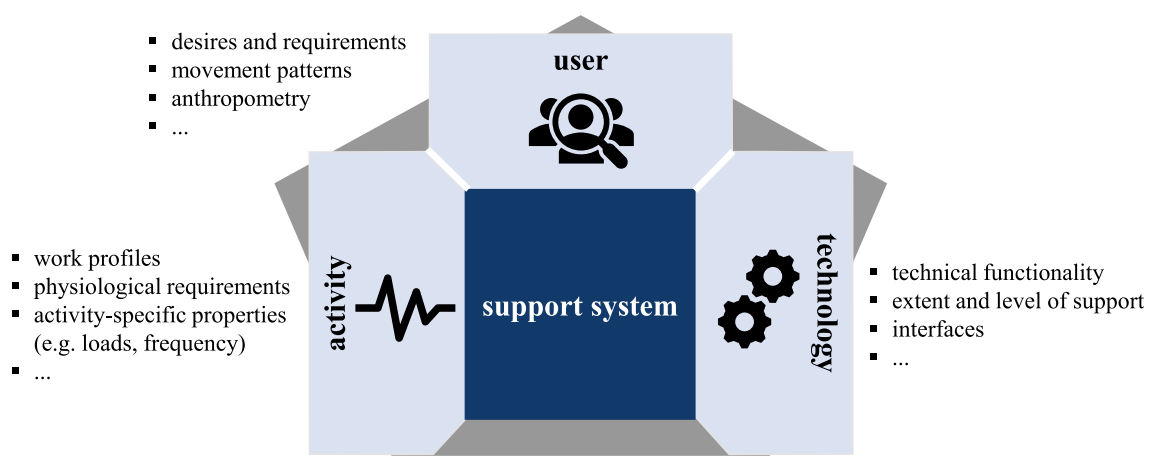

Fig. 1 Characterization of the solution space of support systems, based on [12]

together the two dimensions relational patterns of human and exoskeleton, as well as supported movements of body parts [9]. In this way, the table enables to assign appropriate types of exoskeletons to given support situations. Another visual approach uses a path diagram to classify support situations by the three fundamental determinants spatialtemporal relation, form of coupling, and location of control [15].

All in all, the described approaches characterize and classify different support situations, but there is no comprehensive tool going even further and supporting the selection and evaluation of exoskeletons for specific activities. Therefore, this paper addresses these demands by presenting a generic approach, bringing together the dimensions of technology, users' needs, and tasks in a united concept (see Fig. 1).

\section{Influencing Dimensions of the Decision Process}

Several factors in different dimensions influence the decision-making process of selecting appropriate exoskeletons for specific tasks. The main characteristics of applications in industrial workplaces and technical core properties of exoskeletons are introduced.

\subsection{Characteristics of Tasks in Industrial Workplaces}

Based on preventing MSD, analyses of work profiles are an expedient way to identify and determine (potential) risk factors in industrial applications. Two categories group these factors: the first consists of those addressing the workplace environment and organization (e.g., frequencies, repetition of tasks, or pace of work), while the second type focusses on physical aspects of the activities (e.g., physical exertion, postures, loads, repetition of movements) [16]. According to the causes of MSD, the methods aim to identify exposure factors and evaluate either repetitive movements, strained postures, or the handling of loads [16]. Even though the rapid upper limb assessment (RULA), the Ovako Working 


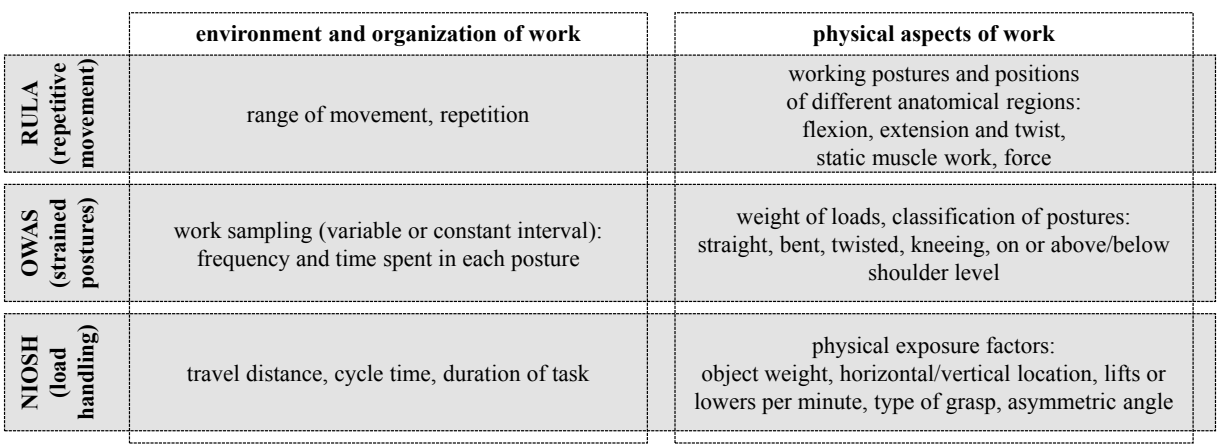

Fig. 2 Characteristic aspects of work based on selected examples

Posture Analyzing System (OWAS), or National Institute for Occupational Safety and Health equation (NIOSH) cover different application scenarios or bodily regions, all of them provide exemplary factors as relevant characteristics for further considerations concerning the analysis of tasks. Figure 2 exemplarily shows aspects to characterize work profiles.

RULA examines factors implying a risk for upper limb disorders [17]. OWAS helps identify, classify and evaluate working postures and enables a structured analysis of frequencies and times spent in strained poses [18]. NIOSH assesses the risks of manual material handling, aiming to determine whether an object or weight is unsafe to handle in lifting and lowering tasks [19]. Even though these methods primarily aim to evaluate existing working conditions and are not designed to select a technical support system, they highlight essential factors in characterizing work profiles.

Another approach to identify characteristics of work profiles is the use of distinguishing features. These generic factors also describe the variance in industrial activities. Factors like dynamics, precision, additional non-task related activities, external process forces, or the variance of tasks complement the aspects of work mentioned above [12, 20].

\subsection{Technical Properties of Exoskeletons}

Besides the characteristics of tasks in industrial workplaces, the specific knowledge about exoskeletons and their technical properties is essential for selecting an appropriate system. In order to provide crucial support in the respective field of application, the importance of different functionalities of exoskeletons varies with their requirements. Differentiating characteristics are, e.g., the mechanism of action, supported bodily region, intended use, power requirements, and construction material $[6,7,8,21]$. Table 1 shows the core characteristics and associated explanations.

Moreover, the characteristics of the system may restrict the possible use [9]. E.g., the design of an exoskeleton possibly influences the potential application, as its size or weight 
Table 1 Core characteristics of exoskeletons (in alphabetical order)

\begin{tabular}{l|l}
\hline characteristics & explanation \\
\hline $\begin{array}{l}\text { actuation and } \\
\text { control }\end{array}$ & $\begin{array}{l}\text { method of actuation (e.g., active, passive), recognition of intention, sensor } \\
\text { technology }\end{array}$ \\
\hline extent of support & supported bodily regions (e.g., upper extremities, back) \\
\hline form of support & enable/empower/stabilize/facilitate/add movements \\
\hline level of support & performance support (torque, weight), degree of support (0-100\%) \\
\hline $\begin{array}{l}\text { morphological } \\
\text { structure }\end{array}$ & $\begin{array}{l}\text { force transmission, stiffness (e.g., rigid, soft, hybrid), material (e.g., } \\
\text { lightweight) }\end{array}$
\end{tabular}

may hinder the user in executing his task. Considering the distance between the exoskeleton and the human body is also paramount, as it could be impossible to access narrow passages. According to the resemblance to human anthropometry, exoskeletons have different ranges of motion and, thus, enable diverse movements [8].

\section{Development of a Tool Providing Decision Support}

A decision-supporting tool including multicriterial factors may aid the selection of an appropriate exoskeleton in a structured manner. Before the approach is presented in detail, relevant characterization dimensions are determined, and the display form is specified. According to the human hybrid robot concept, the tool should consider the influencing factors user, technical system, and task [22].

\subsection{Determination of Decision-supporting Dimensions}

Even though there is a large variety of tasks appearing in workplaces of different industries [17], three elementary dimensions generally characterize the activities:

(1) Properties of tasks: Relevant properties of activities for selecting an exoskeleton, e.g., dynamics, bodily region, posture, weights, variance (concerning weight and tools), travel distances, and ranges of motion.

(2) Work profiles: Deriving specific requirements with respect to the properties, based on the work profiles to describe the activities/workplaces.

(3) System characteristics: Each exoskeleton inheres its own functional and morphological characteristics and, thus, differently supports the user.

The main challenge is to link the ambient requirements of work systems with the technical properties of exoskeletons. In order to be purposively applicable in various industries, the approach needs to meet the following criteria: (a) the decision support tool should be generic to cover a wide range of application scenarios, (b) it should address 
different loading cases, and (c) it should leave individual margins of discretion, as the importance of parameters differ for the respective applications.

\subsection{Selection of a Display Method}

For the three main influencing dimensions, a form of presentation needs to visualize the potential suitability of exoskeletons for specific applications in one compact figure. In this regard, a visual display method addresses the various dimensions and raises awareness of the complex selection process best. As a result, a multidimensional matrix has been chosen. It depicts the three dimensions and contrasts the selection alternatives in a structured way for specific applications. Effectively, the matrix enables a generic task modeling and selection of exoskeletons for respective scenarios.

\subsection{Creation and Application of the Decision Support Matrix}

The top of Fig. 3 illustrates the concept of the decision support matrix (DSM). The three main dimensions are: (1) core overall properties with possible characteristics, (2) modeled tasks from industrial workplaces, as well as (3) properties of exoskeletons. The lower part of Fig. 3 shows the four stages to create and apply the DSM in a step-by-step guide.

Step 1 - Selection of relevant properties: The horizontal axis represents the general characteristics as requirements for the system. By the use of rating scales, the properties can be specified. The multicriteria selection process requires the consideration of relevant factors for describing the work profiles. For the specific application, attributes may be individually chosen to characterize activities.

Step 2 - Modeling of activities: This step adds the ambient activities to the matrix. Vertical pillars in each column visualize work profiles for concrete application scenarios. Comparable to a box plot, the ranges of the properties are qualitatively modeled and set the requirements for a successful implementation of appropriate exoskeletons.

Step 3 - Implementation of exoskeletal features: Available exoskeletons with their technical properties are introduced to the matrix. Different lines indicate inherent characteristic values for each system (idealized course with exemplary variance). Before an exoskeleton is selected for implementation, the requirements should be considered thoroughly. The line progressions in the matrix represent real data of different exoskeletons.

Step 4 - Selection of an exoskeleton: Based on defined requirement profiles, the match between the line progressions for different exoskeletons with the modeled pillars of the activities allows a well-founded selection of a system. This indication enables decision-makers to assess whether the implementation of an exoskeleton in the respective application scenario may be sufficient or not.

The matrix may add value by enabling to systematically link the ambient requirements of work systems and the technical properties of the exoskeletons. Thus, it helps to both 


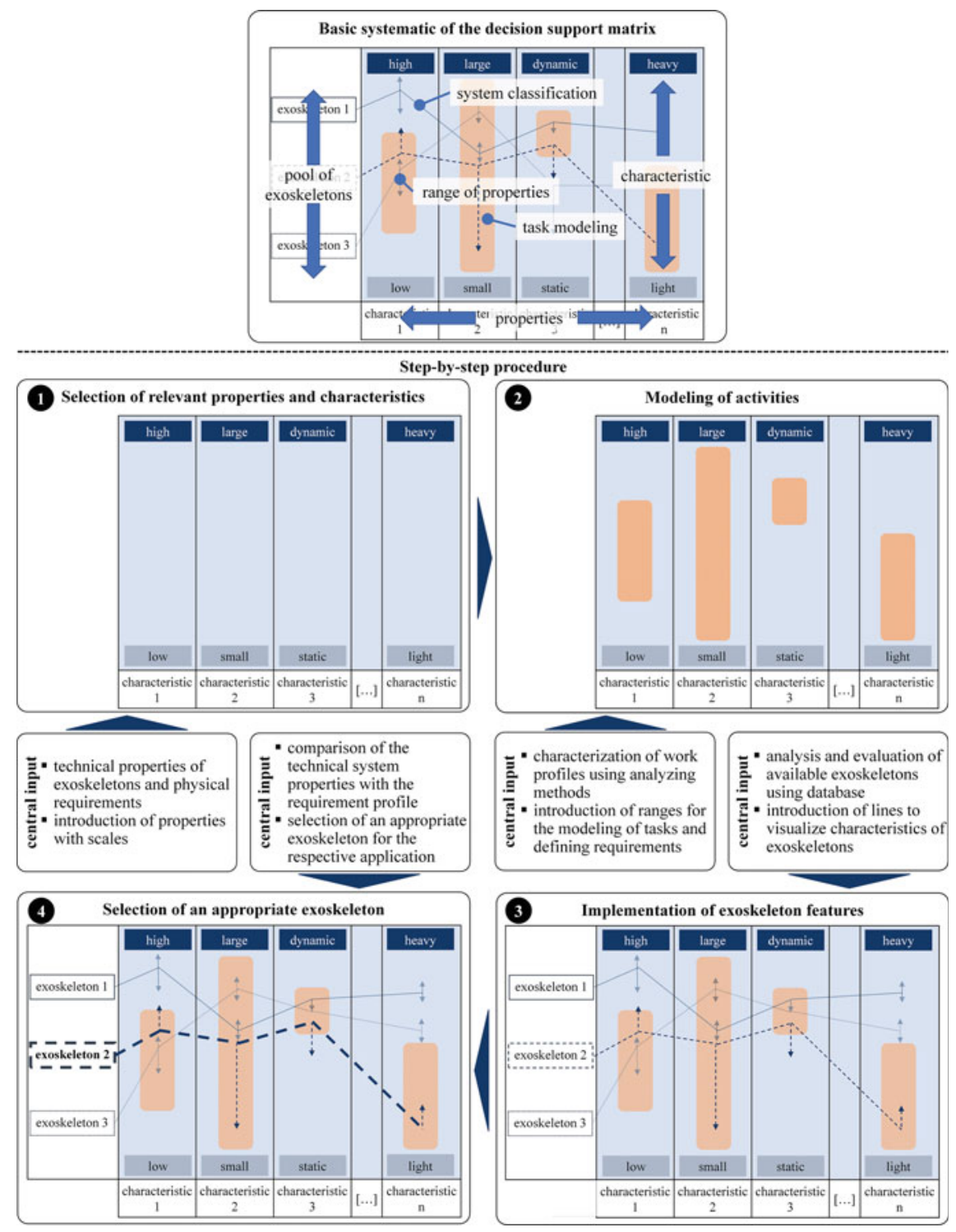

Fig. 3 Basic systematic as well as a step-by-step guide to the creation and application of the decision support matrix

select and evaluate exoskeletons for given tasks. If the matrix becomes confusing due to too many lines, it is highly recommended to distinguish different loading cases and, thus, to create different matrices. 


\section{Application Example}

For a real application scenario, the step-by-step procedure for creating and applying the DSM is explained. This scenario considers manual screwing, assembling, and material handling activities in different workplaces and postures.

Step 1 - Selection of relevant properties: In order to describe the loading cases, technical properties incl. scales need to be defined first. In this example, the properties dynamics, bodily region, (arm) posture, weight, variance, distance, and range of motion are chosen and displayed on the abscissa (see Fig. 4). Except for the bodily region and (arm) posture (discrete scale), the factors can be distributed continuously as possible expressions. Referenced papers, checklists, or calculation tools may support the identification of relevant properties.

Step 2 - Modeling of activities: The three exemplary use cases (1) screwing overhead, (2) screwing with tool changes, and (3) assembling and material handling activities in extended arm positions are considered. Grey-scaled pillars in each column of the matrix model these scenarios. Depending on the expressions of each property, the corridors take up different spaces in the columns. The screwing activity overhead of use case 1, e.g., mainly strains the upper extremities. Conversely, work profile 2 requires different postures and variances due to necessary tool changes. In contrast to the previous cases, scenario 3 includes combined assembly and manual handling activities and, thus, strains different body parts. A high variation concerning dynamics, weights, distances, movement ranges, and postures is characteristic. Vertical pillars in the respective columns of the DSM illustrate these requirements (see Fig. 4). Methods as OWAS, RULA, or NIOSH might help to determine the exact expressions.

Step 3 - Implementation of exoskeletal features: In this example, two different exoskeletons are implemented into the DSM: an active and rigid exoskeleton, as well as a

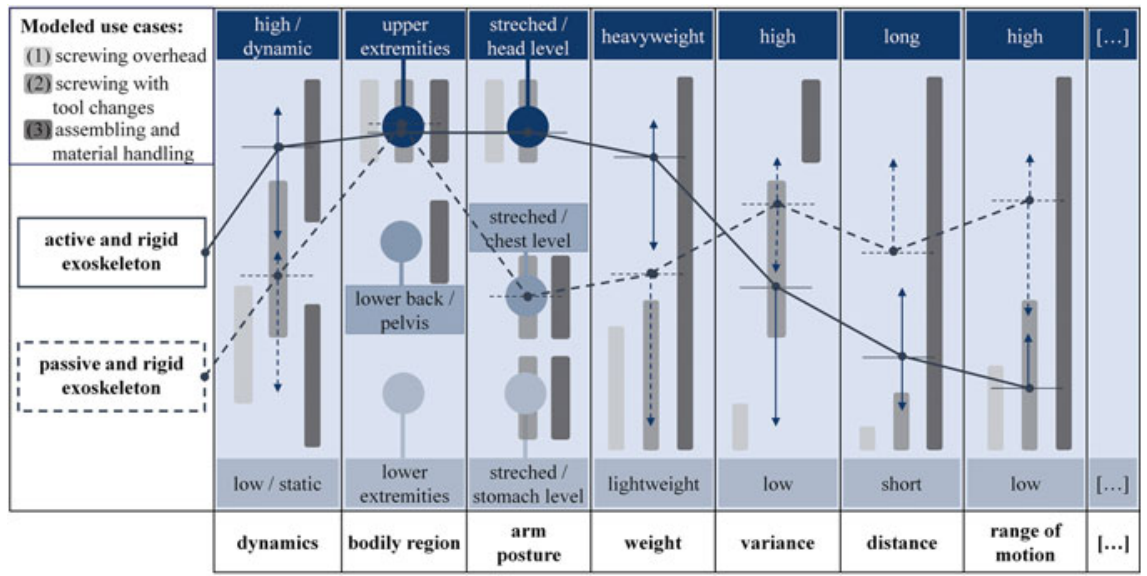

Fig. 4 Decision support matrix for three exemplary loading cases 
passive system. They are visualized by full (active exoskeleton) and dashed lines (passive system), respectively (see Fig. 4). These lines represent the properties of commercial exoskeletons. Due to objectivity and the methodological focus, they are not explicitly named in this example. The vertical arrows illustrate the corridors to cover occurring variance. Datasheets or measured data may help to determine and compare the expressions for each exoskeleton.

Step 4 - Selection of an exoskeleton: The last step schedules the comparison of the exoskeletal properties to the requirements of the work profiles. For an accurate interpretation, minimum requirements should be considered. These implications lead to the following suggestions for this exemplary scenario:

(1) The minimum requirements of use case 1 are met and even surpassed by the active exoskeleton. As a result, this system is well-suited to support users in this use case. The passive exoskeleton is not suitable, as it does not support overhead activities.

(2) Neither the active nor the passive exoskeleton can adequately support all the different postures. But all other minimum requirements are met by both systems. The appropriateness of the corresponding exoskeletons for this use case should be considered in more detail.

(3) Neither the active nor the passive exoskeleton meets the requirements of use case 3 (e.g., concerning varying dynamics, back support, high variance). As a result, both systems cannot fully support all tasks. Nevertheless, each system can assist single activities of the work profile.

In short, the possible eligibility of exoskeletons for a task is given, if the line characterizing the specific system matches the range of the highlighted pillars of the respective work profiles in the DSM (see Fig. 4).

As the example shows, the matrix may indicate the suitability of different exoskeletons and support the selection process. However, it is always necessary to consider the specific application case detailly. In general, higher expressions for the technical features are more advantageous than lower ones, as the minimum requirements are easier met. Moreover, the chosen aspects underlying the recommendations for the selection should not be the only decisive factor. Other factors, such as acceptance and usability, should also be considered. In order to reduce physical strain and support the workers, it is also crucial to choose an appropriate level of support.

\section{Conclusion and Outlook}

Exoskeletons should be carefully selected for the respective applications, as an inappropriate selection and use may also affect unintended consequences, like restricting the freedom of movement or potentially causing or enhancing MSD [11]. Therefore, this paper has presented a generic and schematic approach to assess the fundamental suitability 
of exoskeletons. Additionally, it may also lead to a higher sensibility and help to identify characteristics of activities.

However, the matrix cannot represent the complex decision problem in its entirety. There is potential left to improve and specify the approach of a decision support matrix, e.g., by adding another dimension considering the specific technical properties of exoskeletons. It may also help distinguish between ambient work profiles and inherent core properties of exoskeletons. Interrelations between the external and internal levels could therefore be addressed more clearly.

In summary, this generic approach may support decision-makers to select an appropriate exoskeleton for their specific industrial application. Further critical evaluation of the decision support matrix may be reached by incorporating it into practical selection processes of exoskeletons. Despite this generic approach presented in the spotlight of exoskeletons, the application of the DSM is not limited to this technology. It is also possible to classify any other kind of (technical) support system in the matrix. In this respect, the matrix aims at a similar effect as the approach of a periodic table for technical support systems does [9]. Even though the DSM cannot represent the complexity of the selection problem, it aids in determining a starting point for a well-founded selection of suitable support devices.

Acknowledgements This article was written as part of the "Exo@Work" research project, sponsored by the German Employer's Liability Insurance Association for Trade and Logistics (BGHW). The authors are solely responsible for the content of the article.

Open Access This chapter is licensed under the terms of the Creative Commons Attribution 4.0 International License (http://creativecommons.org/licenses/by/4.0/), which permits use, sharing, adaptation, distribution and reproduction in any medium or format, as long as you give appropriate credit to the original author(s) and the source, provide a link to the Creative Commons license and indicate if changes were made.

The images or other third party material in this chapter are included in the chapter's Creative Commons license, unless indicated otherwise in a credit line to the material. If material is not included in the chapter's Creative Commons license and your intended use is not permitted by statutory regulation or exceeds the permitted use, you will need to obtain permission directly from the copyright holder.

\section{References}

1. Bloss, R.: Collaborative robots are rapidly providing major improvements in productivity, safety, programing ease, portability and cost while addressing many new applications. Industrial Robot 43, 463-468 (2016)

2. Weidner, R., Linnenberg, C., Hoffmann, N., Prokop, G., Edwards, V.: Exoskelette für den industriellen Kontext: Systematisches Review und Klassifikation. In: 66. Kongress der Gesellschaft für Arbeitswissenschaften: Digitaler Wandel, digitale Arbeit, digitaler Mensch (2020) 
3. Saggiomo, M., Longé, G., Gloy, Y.-S.: Augmented-Reality-basierte Applikation zur Assistenz von Webmaschinenbedienern. Melliand-Textilberichte 96, 22-24 (2016)

4. Eurofound: Sixth European working conditions survey-overview report (2017 update). Publications Office of the European Union, Luxembourg (2017)

5. Bogue, R.: Exoskeletons - a review of industrial applications. Ind. Robot Int J 45, 585-590 (2018)

6. Hensel, R., Keil, M., Mücke, B., Weiler, S.: Chancen und Risiken für den Einsatz von Exoskeletten in der betrieblichen Praxis: https://www.asu-arbeitsmedizin.com/chancen-undrisiken-fuer-den-einsatz-von-exoskeletten/chancen-und-risiken-fuer-den-einsatz-von.

Accessed 25 Aug 2020

7. Kara, D.: Industrial exoskeletons: new systems, improved technologies, increasing adoption. https://www.therobotreport.com/industrial-exoskeletons/. Accessed 22 Sep 2020

8. De Looze, M.P., Bosch, T., Krause, F., Stadler, K.S., O’Sullivan, L.W.: Exoskeletons for industrial application and their potential effects on physical work load. Ergonomics 59, 1-11 (2015)

9. Weidner, R., Karafillidis, A.: Distinguishing support technologies. A general scheme and Its application to Exoskeletons. In: Karafillidis, A., Weidner, R. (Hrsg.): Developing support technologies - integrating multiple perspectives to create assistance that people really want, pp. 85-100 (2018)

10. Bogue, R.: Robotic exoskeletons: a review of recent progress. Ind. Robot Int. J. 42, 5-10 (2015)

11. Fox, S., Aranko, O., Heilala, J., Vahala, P.: Exoskeletons: comprehensive, comparative and critical analyses of their potential to improve manufacturing performance. J Manuf Technol Manage 31, 1261-1280 (2019)

12. Weidner, R., Hoffmann, N.: Technische Unterstützungssysteme - Menschen gewollt. In Hartard, S., Schaffer, A. (Hrsg.): Mensch und Technik - Perspektiven einer zukunftsfähigen Gesellschaft, pp. 225-246 (2020)

13. DGUV: Checkliste für den betrieblichen Einsatz von Exoskeletten: https://publikationen.dguv. de/regelwerk/publikationen-nach-fachbereich/handel-und-logistik/physische-belastungen/ 3909/fbhl-020-checkliste-fuer-den-betrieblichen-einsatz-von-exoskeletten?c=54. Accessed 03 Feb 2021

14. Japet: Ergonomic evaluation tool. https://en.japet.eu/calculator/. Accessed 03 Feb 2021

15. Weidner, R., Argubi-Wollesen, A., Karafillidis, A., Otten, B.: Human-machine integration as support relation: individual and task-related hybrid systems in industrial production. I-Com 16, 143-152 (2017)

16. Gomez-Galan, M., Perez-Alonso, J., Callejon-Ferre, A.-J., Lopez-Martinez, J.: Musculoskeletal disorders: OWAS review. Ind. Health 55, 314-337 (2017)

17. McAtamney, L., Corlett, E.N.: RULA: a survey method for the investigation of work-related upper limb disorders. Appl. Ergonomics 24, 91-99 (1993)

18. Karhu, O., Kansi, P., Kuorinka, I.: Correcting working postures in industry: a practical method for analysis. Appl. Ergonomics 9, 199-201 (1977)

19. Garg, A., Hegmann, K.T., Moore, J.S., Kapellusch, J.M., Bhoyar, P., Thiese, M.S., Merryweather, A., Deckow, G., Bloswick, D., Malloy, E.J.: The NIOSH lifting equation and low-back Pain, Part 1: association with low-back pain in the back: works prospective cohort study. Hum. Factors 56, 6-28 (2014)

20. Argubi-Wollesen, A., Wollesen, B., Leitner, M., Mattes, K.: Human body mechanics of pushing and pulling: analyzing the factors of task-related strain on the musculoskeletal system. Saf. Health Work 8, 11-18 (2017) 
21. Otten, B., Weidner, R., Argubi-Wollesen, A.: Evaluation of a novel active exoskeleton for tasks at or above head level. IEEE Robot. Autom. Lett. 3, 2408-2415 (2018)

22. Weidner, R., Wulfsberg, J.P.: Concept and exemplary realization of human hybrid robot for supporting manual assembly tasks. Procedia CIRP 23, 53-58 (2014)

Open Access This chapter is licensed under the terms of the Creative Commons Attribution 4.0 International License (http://creativecommons.org/licenses/by/4.0/), which permits use, sharing, adaptation, distribution and reproduction in any medium or format, as long as you give appropriate credit to the original author(s) and the source, provide a link to the Creative Commons license and indicate if changes were made.

The images or other third party material in this chapter are included in the chapter's Creative Commons license, unless indicated otherwise in a credit line to the material. If material is not included in the chapter's Creative Commons license and your intended use is not permitted by statutory regulation or exceeds the permitted use, you will need to obtain permission directly from the copyright holder.

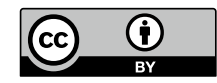

